\title{
Bookreviews
}

\author{
Leif KUllmaN
}

\section{CHANGE AND STABILITY IN THE ALTITUDE OF THE BIRCH TREE-LIMIT IN 'THE SOUTHERN SWEDISH SCANDES 1915-1975}

\section{Acta P'hytogeographica Suecica 65. - Uppsala 1979, 121 pp., 78 Fig. and 14 Tab.}

The book deals with the altitudinal birch tree-limit depending on a complex of factors, especially climatic, edaphic and human. The traditional Scandinavian research occupied with problems of tree- and forest-limit at the beginning of the present century suggested the comparison of earlier data with the new situation. H. SMrTH's results from $1915-1916$ in the southern part of the Scandes mountains were the basis for author's study in 1970 - 1975.

L. KuLLMAN thoroughly investigated present day altitudes of forest-and tree-limit, mature stem limit, species-limit, age-determination transect on 213 localities together with calculation of past tree-limit. Besides the climatical and topographical description of investigatted area, human activity was discussed. The author supposed that the cessation of human impact was not the primary cause of tree-limit changes.

A rising of tree-limit was recorded for $75 \%$ of the sites, the rest was unchanged. The observed increases were correlated to a complex of factors of which the effect of climate (in interaction with edaphic factors) is most important. The basic cause for the raising of the tree-limit was climatic amelioration, especially during the warm summers of $1930-1939$. This favourable period causing an early thaw and a rapid drying of the soil provided good conditions for seed germination and seedling establishment. Decisive changes of tree-limit depend on local snow conditions. The localities which have much snow and late thawing showed raised limits, Little or no change in tree-limit was observed on sites with a shallow snow cover. Birches growing in the tree limit ecotone are mechanicaly damaged by the weight of the snow during the thaw. The author expects the tree-limit to rise further in areas characterised by a heavy accumulation of snow.

The study is interesting for comparison with our conditions of tree- and forest-limit formed by conifers. Although the definions for birch (trees at least $2 \mathrm{~m}$ heigh; forest is characterised by a minimal area $5 \times 5 \mathrm{~m}$ and a minimum of 10 tree-sized stems) differ from the definitions for spruce for example, it is possible to utilize the information of the study in out work.

The applied methods used in the book reviewed are not complicated and in a simple and appropriate way they express the influence of various factors. Therefore this book will be appreciated by biologists and ecologists. 